\title{
A INSERÇÃO DA EDUCAÇÃO AMBIENTAL NA PRÁTICA PEDAGÓGICA: UMA ANÁLISE SEGUNDO A VISÃO DOS ALUNOS DOS CURSOS TÉCNICOS- INTEGRADOS DO CEFET-RN
}

\author{
Ana Paula Bezerra Costa \\ Graduanda em Tecnologia em Meio Ambiente no CEFETRN \\ bc.anapaula@gmail.com \\ Maria do Socorro Diógenes Paiva \\ Mestre em Engenharia Sanitária em Ambiental e Professora do CEFETRN \\ msocorro@cefetrn.br \\ João Maria Filgueira \\ Mestre em Engenharia da Produção com Ênfase em Qualidade e Professor do CEFETRN \\ imfilgueira@cefetrn.br
}

\section{RESUMO}

O presente artigo relata os resultados obtidos a partir do estudo desenvolvido com alunos dos cursos técnicos integrados do CEFET-RN de Natal, sobre os principais fatores que dificultam a prática da educação ambiental em sala de aula. Para tanto, foi realizada uma pesquisa com aplicação de questionários aos estudantes, em horários normais de aulas durante quatro dias no mês de janeiro do corrente ano. Considerando as informações coletadas, a maioria dos entrevistados define que a falta de discussão sobre o tema é um dos principais obstáculos encontrados. Ao final da pesquisa podemos traçar o perfil desses estudantes e conhecer o nível de consciência ambiental, bem como apresentar sugestões para que o tema seja mais explorado através da interdisciplinaridade e transversalidade.

Palavras Chaves: educação ambiental; consciência ambiental.

\section{THE INSERTION OF THE PRACTICAL AMBIENT EDUCATION IN THE PEDAGOGICAL ONE: AN ANALYSIS ACCORDING TO THE VISION OF STUDENTS OF INTEGRATED TECHNICIAN COURSES OF THE CEFET-RN}

\begin{abstract}
The present article tells the results gotten from the study developed with students of the courses of CEFET-RN, on the main factors that make it difficult the practical of the ambient education in classroom. For in such a way, a research with application of questionnaires to the students was carried through, in normal schedules of lessons during four days in the month of January of the current year. Considering the collected information, the majority of the interviewed ones defines that the lack of quarrel on the subject is one of the main joined obstacles. To the end of the research we can trace the profile of these students and know their level of environmental conscience, as well as presenting suggestions to explore this subject through the integration of all discipline contents.
\end{abstract}

Keywords: environmental education; environmental conscience. 
INSERÇÃO DA EDUCAÇÃO AMBIENTAL NA PRÁTICA PEDAGÓGICA: UMA ANÁLISE SEGUNDO A VISÃO DOS ALUNOS DOS CURSOS TÉCNICOSINTEGRADOS DO CEFET-RN

\section{INTRODUCุÃO}

Muito tem se falado sobre a grande necessidade de preservar os recursos naturais como maneira de manter a sustentabilidade do planeta. Isso pode ser justificado pelo fato de que a Terra sempre foi utilizada pelo homem como fonte inesgotável desses recursos.

À medida que o tempo passa, percebe-se que um número razoável de pessoas tem se manifestado e começado algum trabalho baseado na preservação do Meio Ambiente, porém, a grande maioria da população ainda não atinou para a relevância de alguns temas como degradação ambiental e desenvolvimento sustentável. A degradação do meio ambiente vem aumentando mais e mais, tendo, ao mesmo tempo, seu ritmo acelerado em decorrência da apropriação cada vez maior pelo homem, a fim de suprir suas necessidades. As nossas ações sobre o meio, natural ou construído, estão afetando não só a qualidade de vida atual, como também de futuras gerações. Segundo a análise de Dias (2004) estamos produzindo um mundo que nenhum de nós deseja. A par dos grandes avanços científicos e tecnológicos, o homem experimenta um grande desafio à sua sustentabilidade, fruto de um tipo de educação que 'treina' as pessoas para serem consumidoras úteis, egocêntricas e ignorar as conseqüências dos seus atos.

A tomada de consciência pela população é o primeiro passo para a mudança de comportamento, auxiliando diretamente na preservação dos recursos naturais. Diante dessa realidade, a educação ambiental vem ganhando mais espaço e é vista cada vez mais como tema transversal, importante para essa tomada de consciência.

Tendo em vista o contexto explicitado acima, este trabalho teve como objetivos identificar os principais obstáculos à educação ambiental, assim como traçar o perfil dos alunos dos cursos técnico-integrados do CEFETRN, avaliar se o tema meio ambiente está sendo inserido como tema transversal e verificar a importância da educação ambiental na prática pedagógica do CEFETRN, ou seja, uma análise segundo a visão desses alunos. Para tanto foi realizado um estudo seguindo alguns procedimentos metodológicos como: consulta bibliográfica em livros, revistas, sites, etc. e investigação direta através da aplicação de questionários para os alunos dos sete cursos técnicos: construção civil, controle ambiental, eletrotécnica, geologia e mineração, informática, mecânica e turismo.

Sendo assim, espera se que este estudo enriqueça a discussão sobre Educação Ambiental, contribuindo para a ação de multiplicadores e elaboração de medidas que possam contribuir na prática pedagógica.

\section{CONTEXTUALIZAÇÃO DA EDUCAÇÃO AMBIENTAL}

A Educação Ambiental (EA) surgiu como um processo educativo, de formação da cidadania, com princípios que rompem com a idéia de que as causas dos impactos 
ambientais residem apenas, entre outros fatores, na explosão demográfica, na agricultura intensiva e na crescente urbanização e industrialização. É necessária uma mudança de postura, de hábitos e de costumes. É preciso conservar e preservar, mas, principalmente, educar. Dessa forma ela vem se transformando ao longo dessas últimas décadas como proposta de educação para ajudar na resolução dos novos desafios colocados pelo próprio sistema capitalista vigente que visa o lucro a qualquer custo em detrimento da qualidade dos recursos naturais.

Nesse contexto, a Educação Ambiental se insere como um conjunto de práticas que envolvem não só a conscientização do indivíduo, mas também uma mudança de postura referente às questões ligadas ao meio ambiente. Todos os indivíduos devem ter acesso ao processo de educação ambiental, para que o mesmo possa mudar de atitudes e perceber que é importante para a melhoria da qualidade de vida a preservação do ambiente no qual está inserido.

Assim, a EA tenta despertar em todas as pessoas a consciência de que o ser humano é parte do Meio Ambiente, e mais, ela tenta superar a visão antropocêntrica, que fez com que o homem se sentisse sempre o centro de tudo esquecendo a importância da natureza, da qual é parte integrante.

Para que o conhecimento passe de geração a geração, pessoa a pessoa, é preciso que todos tenham acesso a EA. Segundo a Lei n. 9.795, de 27 de abril de 1999 Art. 2, a educação ambiental é um componente essencial e permanente da educação nacional, devendo estar presente, de forma articulada, em todos os níveis e modalidades do processo educativo, em caráter formal e não-formal. Formal é um processo institucionalizado que ocorre nas unidades de ensino; Enquanto que a Informal se caracteriza por sua realização fora da escola, envolvendo flexibilidade de métodos e de conteúdos e um público alvo muito variável em suas características (faixa etária, nível de escolaridade, nível de conhecimento da problemática ambiental, etc.).

\subsection{Educação Ambiental Como Tema Transversal nos Parâmetros Curriculares Nacionais}

A inserção da temática do Meio Ambiente como tema transversal nos Parâmetros Curriculares Nacionais $(\mathrm{PCNs})^{1}$ é de grande importância, visto que a questão ambiental vem sendo considerada cada vez mais urgente e importante para a sociedade, pois o futuro da humanidade depende da relação estabelecida entre a natureza e o uso pelo homem dos recursos naturais disponíveis. Essa consciência já chegou à escola e muitas iniciativas têm sido desenvolvidas em torno desta questão, por educadores de todo o País.

A intenção deste documento é tratar das questões relativas ao meio-ambiente em que vivemos, considerando seus elementos físicos e biológicos e os modos de interação do homem e da natureza, por meio do trabalho, da ciência, da arte e da tecnologia.

Os PCN's têm como objetivo principal orientar a elaboração e a revisão dos currículos adotados nos ensinos fundamental e médio no Brasil. Sobre meio ambiente, o que eles

\footnotetext{
${ }^{1}$ Foram elaborados entre os anos de 1995 e 1998 por profissionais da educação e de outras áreas.
} 
propõem é uma abordagem transversal do tema. Isso significa que a educação ambiental não é responsabilidade de uma disciplina específica, mas trata-se de um eixo a ser contemplado pelas diversas áreas do conhecimento.

\subsubsection{Tranversalidade e interdisciplinaridade}

O conceito de transversalidade é um tanto complexo para ser colocado em prática. Os PCN's recomendam aos professores a pesquisa individual, em grupo e com os alunos para aprofundarem o conhecimento sobre o tema. Fontes de pesquisa não faltam. Livros, revistas, jornais e programas de TV falam sobre meio ambiente com freqüência. Cabe ao professor encontrar os pontos de encontro da sua área com a temática ambiental e os demais temas transversais como saúde e ética, por exemplo. Esse trabalho torna-se mais fácil quando se adota o conceito de meio ambiente exposto nos parâmetros. Para além da esfera ecológica, os PCN's defendem que a educação ambiental incorpore as dimensões sócio-econômica, política, cultural, histórica e seja trabalhada de acordo com o contexto dos estudantes. É importante que as escolas tenham um projeto pedagógico bem estruturado, que estimule professores, funcionários e alunos a atuarem de forma integrada com a comunidade.

A proposta da transversalidade pode acarretar algumas discussões do ponto de vista conceitual como, por exemplo, a da sua relação com a concepção de interdisciplinaridade. Essa discussão é pertinente e cabe analisar como estão sendo consideradas nos Parâmetros Curriculares Nacionais as diferenças entre os dois conceitos, bem como suas implicações mútuas. Ambas - transversalidade e interdisciplinaridade - se fundamentam na crítica de uma concepção do conhecimento que toma a realidade como um conjunto de dados estáveis e sujeitos a um ato de conhecer isento e distanciado. Mas, diferem uma da outra uma vez que a interdisciplinaridade questiona a segmentação entre os diferentes campos do conhecimento, produzida por uma abordagem que não leva em conta a inter-relação e a influência entre estes.

A transversalidade diz respeito à possibilidade de se estabelecer, na prática educativa, uma relação entre aprender conhecimentos teoricamente sistematizados (aprender sobre a realidade) e as questões da vida real e de uma transformação (aprender na realidade e da realidade). Já a interdisciplinaridade afirma ser necessário ir além da mera justaposição de disciplinas, ao mesmo tempo em que se evita a diluição destas, principalmente no que concerne a possibilidade de relacionar as disciplinas em atividades ou projetos de estudos, pesquisa e ação como prática pedagógica e didática. Uma dessas propostas escolhidas foi o Meio-Ambiente como tema transversal no ensino fundamental e de forma contextualizada no ensino médio (SATO, 1995).

\section{METODOLOGIA: CARACTERIZAÇÃO DO ESTUDO, ELABORAÇÃO DO INSTRUMENTO DE COLETA, POPULAÇÃO E AMOSTRA, COLETA E TABULAÇÃO DE DADOS E ANÁLISE DOS DADOS}

Para o levantamento de dados são necessários alguns conceitos que estão inseridos na Estatística Descritiva. A Estatística nada mais é que a coleta, a apresentação, a análise e a interpretação de dados numéricos de uma amostra (FONSECA, 1984). Para Samara 
(2002), os objetivos da pesquisa são determinados de maneira a trazer as informações que solucionam o problema de pesquisa.

Após a definição do problema a ser estudado, o próximo passo foi a coleta de dados que consistiu na busca desses e relações das variáveis. Essa pode ser de forma direta, quando os dados são recolhidos diretamente na fonte de origem, ou podem ser de forma indireta, quando os dados são obtidos através de uma coleta direta. No presente estudo, os dados foram coletados de maneira direta. A pesquisa descreve a visão dos alunos dos cursos técnico-integrados do CEFETRN em relação à inserção da educação ambiental na prática pedagógica.

A técnica utilizada na presente pesquisa consiste na parte prática da coleta dos dados através da aplicação de questionários em sala de aula. Considerando a recomendação de Fonseca (1990), para uma população de 421 alunos e considerando um erro amostral máximo de 3\% , o tamanho da amostra foi de 408 alunos.

Os questionários foram aplicados no horário normal de aulas na própria Instituição CEFETRN nos dias 3, 4 e 5 de janeiro de 2007. Devido à dificuldade da aplicação a todos os cursos foi necessária a aplicação no dia 15 de janeiro do corrente ano para complementar a pesquisa. Como dito anteriormente, a quantidade de questionários aplicados foi de 421 no total, sendo 66 aos alunos do curso de Edificações, 86 de Controle Ambiental, 43 de Eletrotécnica, 48 de Geologia e Mineração, 82 de Informática, 43 de Mecânica e 53 de Turismo.

A apuração dos dados foi realizada através da tabulação simples de todas as questões, no programa "Statistica 7". As variáveis foram cruzadas a fim de estabelecer o perfil do aluno desses cursos técnico-integrados. A análise dos dados foi realizada com o objetivo de organizar os dados apresentados, através do cruzamento de informações, de forma a fornecer as respostas às perguntas da pesquisa proposta neste estudo. Para isso foram elaborados gráficos no programa "Excel”.

\section{ANÁLISE E APRESENTAC̣ÃO DOS DADOS: PERFIL DOS ALUNOS DOS CURSOS TÉCNICO-INTEGRADOS DO CEFET-RN}

Analisando os resultados de forma sucinta, constatou-se que a maioria dos alunos que responderam ao questionário da pesquisa era do gênero masculino (60\%), e 40\% do gênero feminino (gráfico 01). A faixa etária predominante foi entre 14 e 16 anos, sendo que $64 \%$ eram do $1^{\circ}$ ano do Ensino Médio, e 36\% do $2 \circ$. 


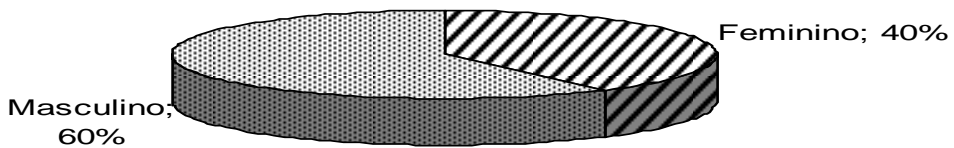

Gráfico 01 - Distribuição dos alunos dos cursos técnico-integrados, de acordo com o gênero, em janeiro de 2007.

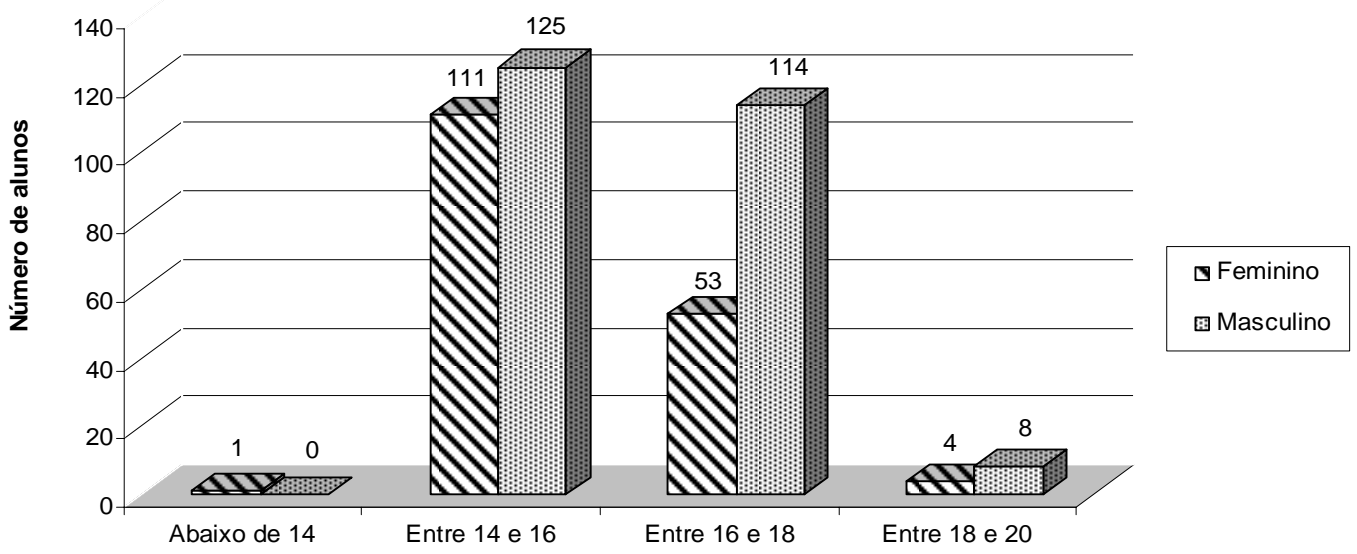

Gráfico 02 - Distribuição dos alunos dos cursos técnico-integrados, de acordo com a faixa etária e o gênero, em janeiro de 2007.

Cruzando as variáveis "Faixa Etária" e "Gênero" (gráfico 02) constatamos que além da predominância da faixa etária ser entre 14 e 16 anos, predomina o sexo masculino em todas as faixas de idade.

Para uma melhor avaliação, questionou-se ainda sobre a abordagem desse tema nas disciplinas; o objetivo dessa questão foi saber se o tema está sendo inserido como transversal e interdisciplinar. Abaixo o gráfico 03 ilustrará os resultados.

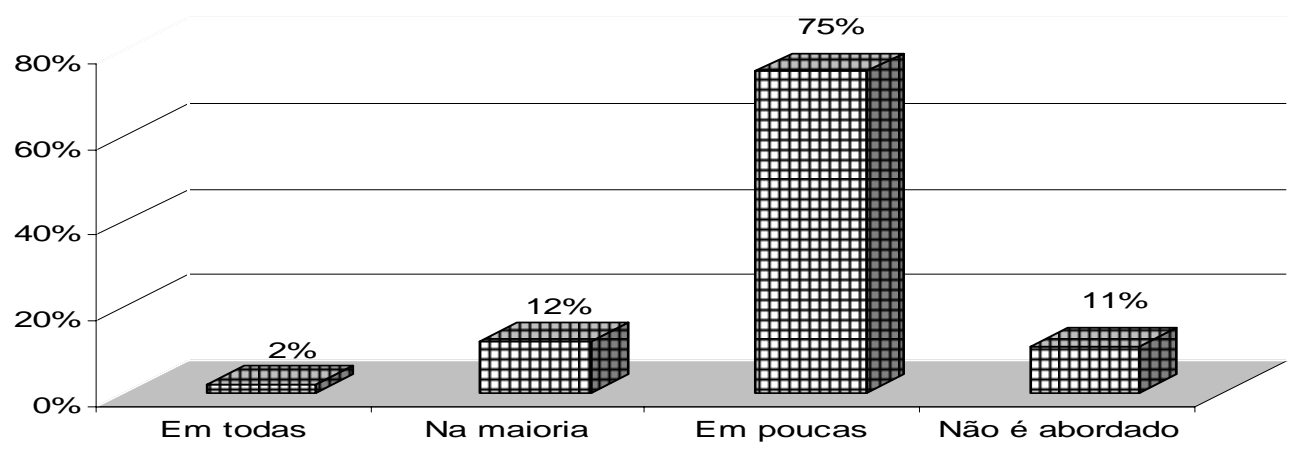

Gráfico 03 - Distribuição dos alunos dos cursos técnico-integrados, de acordo com a abordagem do tema ambiental nas disciplinas, em janeiro de 2007. 
O gráfico 03 demonstra de acordo com 75\% dos alunos dos cursos técnico-integrados que o tema "Meio Ambiente" vem sendo inserido em poucas disciplinas; e apenas 2\% afirmaram que todas as disciplinas abordam o tema. É nesse contexto que voltamos a falar dos PCN's que dizem que a EA deve incorporar outras dimensões: cultural, histórica, política, sócio-econômica e, além disso, afirmam também que tais dimensões devem ser trabalhadas de acordo com o contexto dos estudantes. Por isso, é importante ter um projeto pedagógico bem estruturado, de forma a estimular os professores e os próprios alunos a atuarem de forma integrada.

Foi perguntado aos jovens se há uma priorização da EA no âmbito do CEFETRN. Foram obtidos os resultados contidos no gráfico 04.

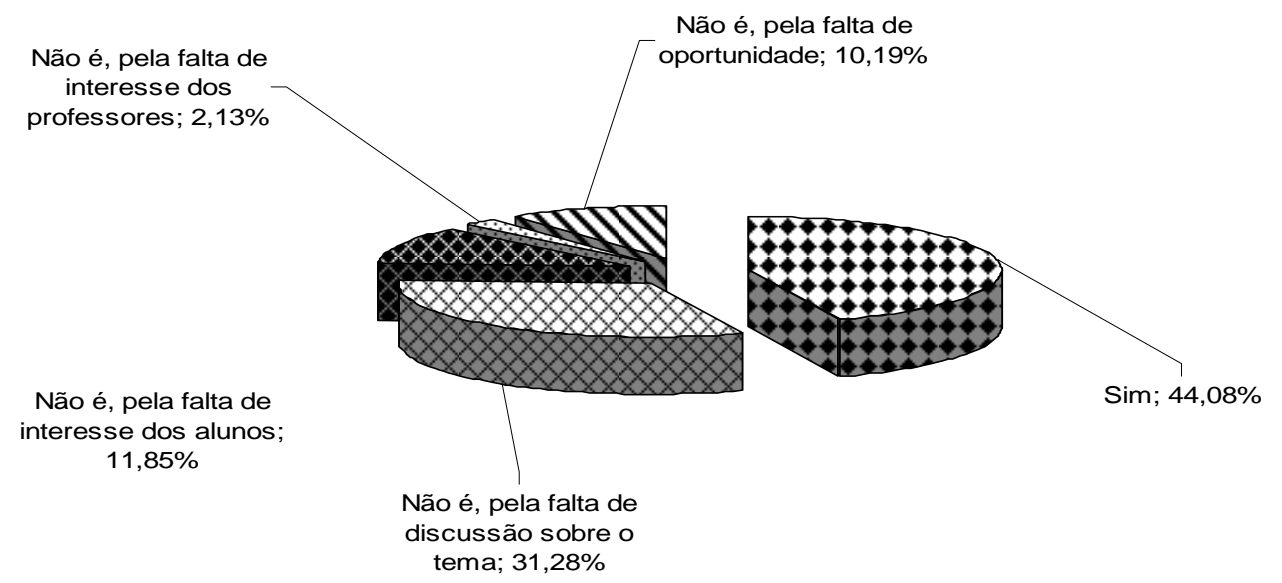

Gráfico 04 - Distribuição dos alunos dos cursos técnico-integrados, de acordo com a abordagem sobre a EA como prioridade no CEFETRN, em janeiro de 2007.

Observa-se a partir do gráfico 04 que 44,08\% dos alunos afirmam que a EA é priorizada em sala de aula. Em contraposição a essa pequena maioria, 31,28\% disseram que não há prioridade por causa da falta de discussão do tema, enquanto que 11,85\% exprimem que é por falta de interesse dos próprios alunos; $10,19 \%$ responderam que se daria prioridade se houvesse mais oportunidades e uma pequena parcela, 2,13\% culpou os professores pela falta de prioridade.

É nesse ponto que voltamos a falar novamente na transversalidade do tema. Segundo SATO (2000), a transversalidade em algumas instituições como a UFMT e a UNEMAT, assegura uma melhor qualidade nas atividades, em função do trabalho coletivo. As instituições não-governamentais (ONG's) também podem auxiliar em atividade de EA. Pensando assim, interrogamos sobre a participação em ONG's relacionadas à questão ambiental e também a participação em atividades que tratam do mesmo assunto.

A partir do gráfico 5, constatamos que quase não há participação dos estudantes em atividades relacionadas ao tema "Meio Ambiente" dentro da própria instituição de ensino, 91,47\% corresponde a um total de 385 estudantes. Apenas 7,35\% já participaram ou participam de atividades como projeto de extensão, programa ou campanha ambiental; 


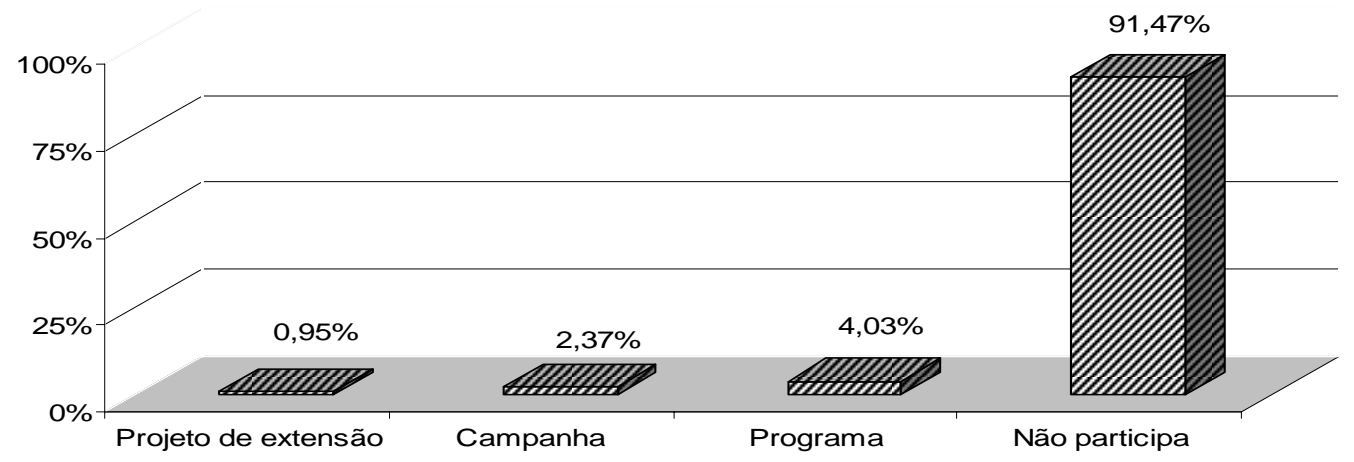

Gráfico 05 - Distribuição dos alunos dos cursos técnico-integrados, de acordo com a participação em atividades "ambientais” no CEFETRN, em janeiro de 2007.

O gráfico 6 mostra por qual meio de comunicação os alunos obtêm informações sobre a questão ambiental; eles responderam quase com unanimidade que a televisão é portadora dessas informações.

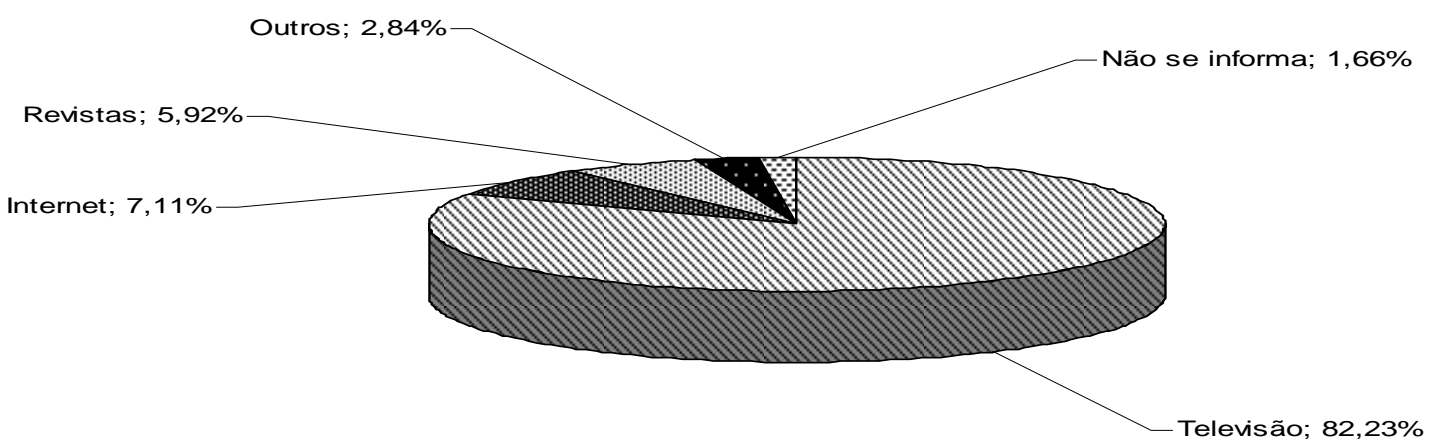

Gráfico 06 - Distribuição dos alunos dos cursos técnico-integrados, de acordo com os meios de comunicação que informam sobre as questões ambientais, em janeiro de 2007.

Questionados sobre alguns temas ambientais tais como Sistema de Gestão Ambiental (SGA), ISO 14.000, Desenvolvimento Sustentável e Agenda 21, apenas 2\% conhecem todos os temas, $19 \%$ têm vaga idéia sobre os temas, $3 \%$ sabem o que é Agenda $21,1 \%$ sabe o que é ISO 14.000, 30\% sabem o que é Desenvolvimento Sustentável e 45\% desconhecem todos os temas, infelizmente (ver gráfico 07). 


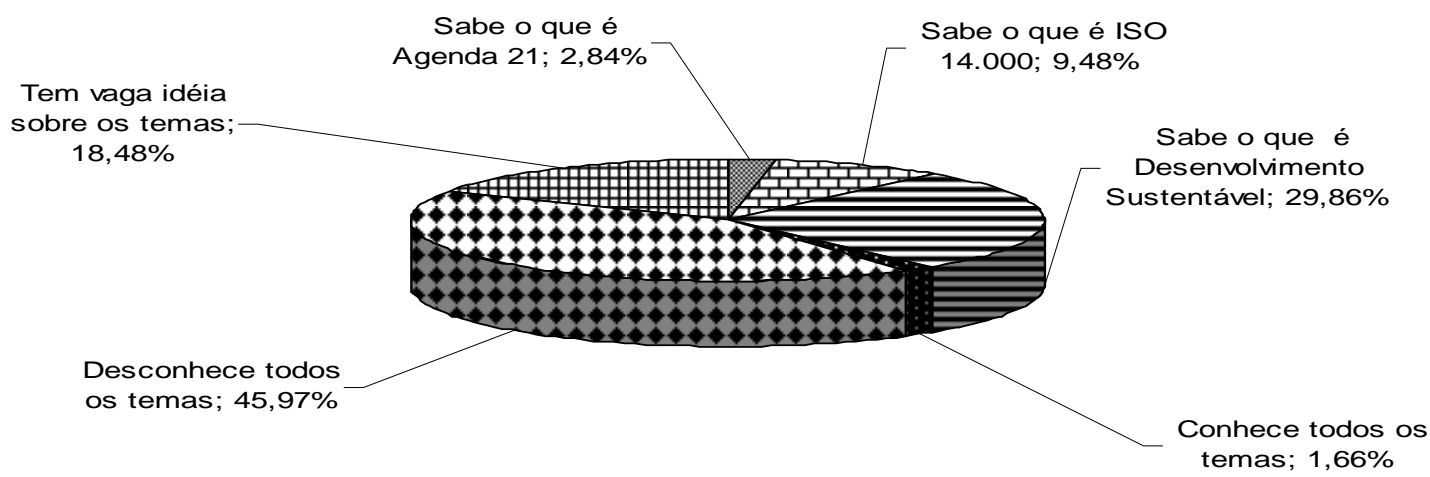

Gráfico 07 - Distribuição dos alunos dos cursos técnico-integrados, de acordo com o conhecimento de alguns temas ambientais, em janeiro de 2007.

A fim de saber o significado de "Meio Ambiente" para os estudantes, perguntamos: como o "Meio Ambiente" é visto por você? As respostas, levando em conta a tipologia proposta por Sauvè (1997) com algumas modificações, encontram-se na tabela I, a seguir.

Tabela I - Percepção do Meio Ambiente pelos alunos dos cursos técnico-integrados.

\begin{tabular}{lc}
\hline \multicolumn{1}{c}{ Ambiente } & $(\%)$ \\
\hline Como natureza & $51 \%$ \\
Como problema & $1 \%$ \\
Como lugar para viver & $28 \%$ \\
Como um recurso & $6 \%$ \\
Como biosfera & $12 \%$ \\
Respostas desconexas & $2 \%$ \\
\hline
\end{tabular}

As respostas corresponderam ao que era esperado. A maioria respondeu que vê o Meio Ambiente como natureza, um lugar para viver e biosfera. No entanto, apesar de poucas pessoas terem dito que vêem como problemas, devemos atentar para isso, o Meio Ambiente não pode ser visto como problema uma vez que dependemos totalmente dele para sobreviver.

Aproveitando a oportunidade, perguntamos para eles quem deveria resolver os problemas ambientais. As respostas estão na tabela II a seguir.

Tabela II - Quem deve ajudar a resolver os problemas ambientais?

\begin{tabular}{lc}
\hline \multicolumn{1}{c}{ Respostas } & $(\%)$ \\
\hline Você individualmente & $14 \%$ \\
ONG's & $1 \%$ \\
Poder público & $15 \%$ \\
Escolas & $2 \%$ \\
Comunidade reunida & $66 \%$ \\
Outros & $2 \%$ \\
\hline
\end{tabular}


Os estudantes disseram que a união de toda a comunidade ajudará a solucionar os problemas ambientais. Apesar disso, devemos relembrar o seguinte: para a comunidade ajudar na resolução desse tipo de problema, é preciso que cada pessoa dê o primeiro passo e conscientize-se que os recursos naturais são esgotáveis.

\section{CONCLUSÃO E RECOMENDAÇÕES}

O trabalho mostrou a visão dos estudantes dos cursos técnico-integrados do CEFETRN. A pesquisa feita em salas de aula possibilitou traçar o perfil desses alunos, formado em sua grande maioria por indivíduos do gênero masculino (60\%) e faixa etária predominantemente entre 14 e 16 anos, representando 57\% do total. O predomínio do sexo masculino está presente também em todas as faixas etárias do estudo.

A realização desse estudo proporcionou também a verificação da inserção do tema "Meio Ambiente" como transversal, além de ter possibilitado a investigação da importância da educação na prática pedagógica.

Infelizmente, são poucas as disciplinas que contemplam o tema ambiental segundo a maior parte dos alunos (75\%). O que pode contribuir para o não interesse dos alunos sobre a questão ambiental, uma vez que eles não têm espaço durante as aulas para discussão acerca da temática. Dentro desse contexto de priorização da EA, 44,08\% afirmam que a questão é priorizada no CEFETRN; Porém 55,45\% negaram, e alegaram os seguintes motivos para a não prioridade: falta de interesse dos professores $(2,13 \%)$, falta de oportunidade $(10,19 \%)$, falta de interesse dos próprios alunos $(11,85 \%)$ e falta de discussão sobre o tema $(31,28 \%)$. Diante disso, torna-se necessário um projeto pedagógico que possa abranger o tema ambiental nas disciplinas e os alunos precisam buscar mais informações acerca do tema, através de informativos, jornais, revistas, ou até mesmo desenvolvendo trabalhos que possuam essa temática.

As organizações não-governamentais podem auxiliar a prática da educação ambiental, assim como atividades relacionadas a essa área. De acordo com as respostas são poucos os que desenvolvem alguma atividade ambiental no próprio CEFETRN. Dentre os poucos 0,95\% participaram de projetos de extensão, 2,37\% de campanhas na área e 4,03\% de algum programa também relacionado à área.

Os meios de comunicação também exercem um papel importante na divulgação de informações relacionadas ao Meio Ambiente, e quando foram questionados sobre qual o meio que mais transmite tais informações, a maior parte dos estudantes $(82,23 \%)$ afirmou que a televisão é o principal. Ficando em segundo lugar a internet com 7,11\%, em terceiro as revistas 5,92\% e em quarto outros meios de comunicação 2,84\%. O fato dos alunos ter respondido que a televisão é o principal meio responsável pela divulgação da questão ambiental mostra que, aparentemente, as aulas ainda não abordam frequentemente o tema, e seria necessário um planejamento para elucidar o tema.

Em relação ao conhecimento de temas ambientais (Sistema de Gestão Ambiental (SGA), ISO 14.000, Desenvolvimento Sustentável e Agenda 21) a maior parte desconhece todos (45\%). Porém 30\% do total garantem saber o que é Desenvolvimento Sustentável; isso é 
bastante importante porque é através desse desenvolvimento que começaremos a tentar preservar nosso planeta Terra.

O significado do termo "Meio Ambiente" é interpretado para a maior parte (51\%) dos alunos como "natureza", o que não deixa de ser verdade. É importante salientar que tudo o que está ao nosso redor faz parte do Meio Ambiente. Apenas 1\% vê o Meio Ambiente como problema. Esse pequeno número ainda não adquiriu a consciência de que o ambiente em que vivemos é crucial para a existência de qualquer espécie.

A comunidade reunida é quem deve ajudar a resolver os problemas ambientais, segundo $66 \%$ dos entrevistados. Muito embora, uma parte deles concorde que cada indivíduo deve exercer seu papel na sociedade e o poder público também deve contribuir.

A realização desta pesquisa contribuiu para um conhecimento sobre métodos de pesquisa de opinião, melhor utilização de softwares como o "Statistica" e o "Excel", além de possibilitar o conhecimento acerca do processo pedagógico utilizado atualmente.

Enfim o estudo possibilitou identificar os principais fatores que dificultam a prática da Educação Ambiental no CEFETRN como, por exemplo, a não abordagem do tema de forma transversal, o fato da inserção da temática em poucas disciplinas e a falta de discussão.

Baseando-se na análise e na interpretação dos resultados da pesquisa, algumas recomendações são propostas aos diretores, professores e pedagogos do CEFETRN:

- Maior inserção da questão ambiental como tema transversal;

- Orientação aos alunos sobre os temas ambientais como Agenda 21, ISO 14.000, SGA, Desenvolvimento Sustentável se possível desde o $1^{\circ}$ ano do $2^{\circ}$ grau;

- Incentivo a participação em atividades relacionadas ao tema - campanhas, ONG's;

- Colaboração no desenvolvimento de trabalhos, projetos e pesquisa sobre a temática;

- Discussão em grupos de estudo, debates;

- Maior esclarecimento sobre os programas desenvolvidos nessa área dentro e fora do CEFETRN;

\section{REFERÊNCIAS}

1. BRASIL. Lei no 9.795 de 27 abril de 1999 Dispõe sobre a educação ambiental, institui a Política Nacional de Educação Ambiental e dá outras providências. Diário oficial da União, Brasília, p.1. abr. 1999.

2. DIAS, Genebaldo Freire. Educação ambiental: princípios e práticas. 9.ed. São Paulo: Gaia, 2004.

3. FONSECA, Jairo Simon. Curso de Estatística. São Paulo: Atlas, 1998.

4. SAMARA, Beatriz Santos e BARROS, José Carlos de; Pesquisa de marketing: Conceitos e Metodologia. 3 ed. São Paulo: Prentice Hall, 2002. 
5. SATO, Michèle. Formação em educação ambiental - da escola à comunidade. In COEA/MEC (org.) Panorama da Educação Ambiental no Brasil. Brasília: MEC, março de 2000, 5-13

6. SATO, Michèle. Educação ambiental. São Carlos: Rima, 2004.

7. SAUVÉ, L. Educação Ambiental e Desenvolvimento Sustentável: uma análise complexa. Rev. Educ. Pub., v 6, n¹0, pp.72-102, 1997. 